\title{
Parametric Sensitivity in a Generalized Model for Atmospheric Pressure Chemical Ionization Reactions
}

\section{Lattouf, Elie}

2021-08-04

Lattouf , E , Anttalainen , O A , Kotiaho , T , Hakulinen , H I , Vanninen , P \& Eiceman , G A 2021 , ' Parametric Sensitivity in a Generalized Model for Atmospheric Pressure Chemical Ionization Reactions ' , Journal of the American Society for Mass Spectrometry , vol. 32 , no. pÿ8 , pp. 22182226 . https://doi.org/10.1021/jasms.1c00158

http://hdl.handle.net/10138/334409

https://doi.org/10.1021/jasms.1c00158

cc_by

publishedVersion

Downloaded from Helda, University of Helsinki institutional repository.

This is an electronic reprint of the original article.

This reprint may differ from the original in pagination and typographic detail.

Please cite the original version. 


\title{
Parametric Sensitivity in a Generalized Model for Atmospheric Pressure Chemical Ionization Reactions
}

\author{
Elie Lattouf,* Osmo Anttalainen, Tapio Kotiaho, Hanna Hakulinen, Paula Vanninen, and Gary Eiceman
}

Cite This: J. Am. Soc. Mass Spectrom. 2021, 32, 2218-2226

Read Online

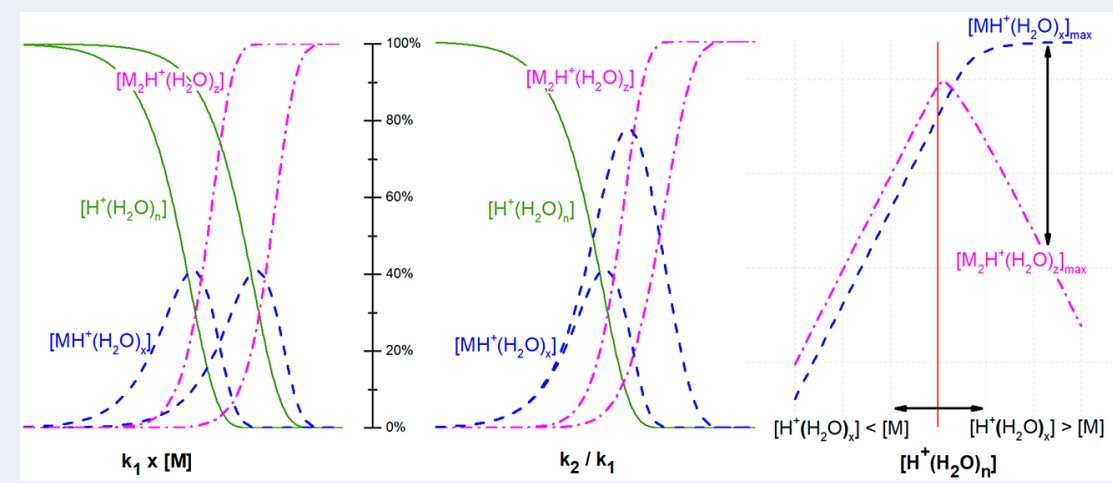

ABSTRACT: Gas phase reactions between hydrated protons $\mathrm{H}^{+}\left(\mathrm{H}_{2} \mathrm{O}\right)_{n}$ and a substance $\mathrm{M}$, as seen in atmospheric pressure chemical ionization (APCI) with mass spectrometry (MS) and ion mobility spectrometry (IMS), were modeled computationally using initial amounts of $[\mathrm{M}]$ and $\left[\mathrm{H}^{+}\left(\mathrm{H}_{2} \mathrm{O}\right)_{n}\right]$, rate constants $k_{1}$ to form protonated monomer $\left(\mathrm{MH}^{+}\left(\mathrm{H}_{2} \mathrm{O}\right)_{x}\right)$ and $k_{2}$ to form proton bound dimer $\left(\mathrm{M}_{2} \mathrm{H}^{+}\left(\mathrm{H}_{2} \mathrm{O}\right)_{z}\right)$, and diffusion constants. At $1 \times 10^{10} \mathrm{~cm}^{-3}(0.4 \mathrm{ppb})$ for $\left[\mathrm{H}^{+}\left(\mathrm{H}_{2} \mathrm{O}\right)_{n}\right]$ and vapor concentrations for $\mathrm{M}$

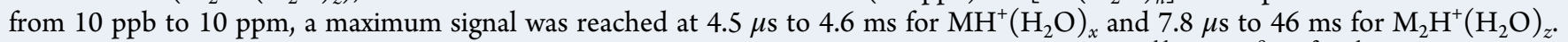
Maximum yield for protonated monomer for a reaction time of $1 \mathrm{~ms}$ was $\sim 40 \%$ for $k_{1}$ from $10^{-11}$ to $10^{-8} \mathrm{~cm}^{3} \cdot \mathrm{s}^{-1}$, for $k_{2} / k_{1}=0.8$, and specific values of $[\mathrm{M}]$. This model demonstrates that ion distributions could be shifted from $\left[\mathrm{M}_{2} \mathrm{H}^{+}\left(\mathrm{H}_{2} \mathrm{O}\right)_{z}\right]$ to $\left[\mathrm{MH}^{+}\left(\mathrm{H}_{2} \mathrm{O}\right)_{x}\right]$ using excessive levels of $\left[\mathrm{H}^{+}\left(\mathrm{H}_{2} \mathrm{O}\right)_{n}\right]$, even for $[\mathrm{M}]>10 \mathrm{ppb}$, as commonly found in APCI MS and IMS measurements. Ion losses by collisions on surfaces were insignificant with losses of $<0.5 \%$ for protonated monomer and $<0.1 \%$ for proton bound dimer of dimethyl methylphosphonate (DMMP) at $5 \mathrm{~ms}$. In this model, ion production in an APCI environment is treated over ranges of parameters important in mass spectrometric measurements. The models establish a foundation for detailed computations on response with mixtures of neutral substances.

KEYWORDS: atmospheric pressure chemical ionization, reaction kinetics, hydrated proton, rate constant, vapor concentration, protonated monomer, proton bound dimer

\section{INTRODUCTION}

Analytical response in atmospheric pressure chemical ionization (APCI) mass spectrometry (MS $)^{1-4}$ and ion mobility spectrometry (IMS) at ambient pressure ${ }^{5,6}$ is governed by gas phase reactions between analyte neutrals and reagent ions, often derived from proton clusters in positive polarity. Such reactions occur in a significant number of ion sources for $\mathrm{MS}^{7,8}$ including corona discharges, ${ }^{9,10}$ electrospray ionization, ${ }^{11-13}$ dielectric barrier discharges, ${ }^{14,15}$ and soft X-rays. ${ }^{16-18}$ One stable and reliable source at ambient pressure, the beta emitter ${ }^{63} \mathrm{Ni}$, was used in early API MS instruments ${ }^{1}$ and can be found in IMS drift tubes in use today. ${ }^{19,20}$ The foundations for understanding gas phase ion-molecule reactions were developed and refined by the mid-1970s ${ }^{21}$ with a broad experimental record for mass spectrometry including chemical ionization $\mathrm{MS}^{22-24}$ and studies with ionization detectors. ${ }^{25-28}$ These reactions as shown in eq 1 for reactions between hydrated protons (reagent) and substances M (analyte) commonly occur at elevated or ambient pressure with ions at thermal energies. Favorable interactions between $\mathrm{M}$ and $\mathrm{H}^{+}\left(\mathrm{H}_{2} \mathrm{O}\right)_{n}$ form an energetic intermediate $\left(\mathrm{MH}^{+}\left(\mathrm{H}_{2} \mathrm{O}\right)_{n}\right) *$ which undergoes loss of neutrals to form a protonated monomer, $\mathrm{MH}^{+}\left(\mathrm{H}_{2} \mathrm{O}\right)_{x}$ :

$$
\underset{\substack{\text { hydrated proton/ } \\ \text { reactant or reagent ion }}}{\mathrm{H}^{+}\left(\mathrm{H}_{2} \mathrm{O}\right)_{n}}+\underset{\text { analyte }}{\mathrm{M}} \leftrightarrow \underset{\substack{\text { protonated } \\ \text { monomer }}}{\mathrm{MH}^{+}\left(\mathrm{H}_{2} \mathrm{O}\right)_{x}}+\underset{\text { neutral }}{y \mathrm{H}_{2} \mathrm{O}}
$$

Received: May 10, 2021

Revised: June 22, 2021

Accepted: June 23, 2021

Published: July 15, 2021 
Residence times and collision frequencies are often sufficient to result in larger cluster ions such as proton bound dimers shown in eq 2 .

$$
\underset{\substack{\text { protonated } \\ \text { monomer }}}{\mathrm{MH}^{+}\left(\mathrm{H}_{2} \mathrm{O}\right)_{x}}+\underset{\text { analyte }}{\mathrm{M}} \leftrightarrow \underset{\substack{\text { proton } \\ \text { bound } \\ \text { dimer }}}{\mathrm{M}_{2} \mathrm{H}^{+}\left(\mathrm{H}_{2} \mathrm{O}\right)_{z}}+\underset{\text { neutral }}{\mathrm{wH}_{2} \mathrm{O}}
$$

While proton bound trimers can form at subambient temperatures and are observed in mobility spectra, ion lifetimes are submillisecond at or above $25^{\circ} \mathrm{C}$ and are not commonly seen in applications of IMS today with 1 to $10 \mathrm{~ms}$ time scale. ${ }^{29,30}$ Only reactions with hydrated protons are considered in models developed here although recent studies have demonstrated that precursor ions including $\mathrm{O}_{2}^{+}$can be utilized at high electric fields and reduced pressures. ${ }^{31}$

In more a generalized expression, the waters of hydration in eq 1 can be replaced by solvent molecules or other substance such as acetone or ammonia to control or enhance selectivity of response in some IMS and MS measurements. ${ }^{5,6,32,33}$ Details on reaction enthalpies, mechanisms, and influences of ion structures were extensively explored from $\sim 1965$ to 1990 for reactions in eqs 1 and 2 with ion sources at high or ambient pressure. ${ }^{34-43}$ Interest was given particularly to refined models of the Langevin rate constant ${ }^{44}$ and detailed descriptions of bimolecular collisions. ${ }^{45}$ Significantly, only a limited experimental record, obtained largely at subambient pressures using selected ion flow tube mass spectrometry, exists on rate constants specifically for hydrated protons, and these studies were from Kebarle et al., ${ }^{38}$ Bohme et al., ${ }^{42,43}$ Castleman et al., $^{46,47}$ and others ${ }^{48,49}$ are also relevant. Rate constants for formation of proton bound dimers are known only from studies with ion mobility spectrometry. ${ }^{50}$

Insights into reaction kinetics have been used in several APCI reaction studies where models were developed to predict or interpret responses in APCI MS or IMS, and these studies were largely targeted to specific designs of technology or substances. ${ }^{51-53}$ In a model of response with reactions in a cylindrical source as found in early APCI MS designs, Siegel described ion density of positive and negative ions formed from a beta emitter. ${ }^{54} \mathrm{~A}$ thorough discussion was given to the production of ions and their losses from recombination and diffusion with an emphasis on source parameters and design. This model was adapted and extended by Ketkar et al. and compared to analytical response in APCI MS with a corona discharge ion source. ${ }^{55}$ The change in response to dimethyl methylphosphonate (DMMP) in the presence of a second constituent, diisopropyl methylphosphonate (DIMP), was determined experimentally and compared favorably with predicted values for reaction times of $0.1 \mathrm{~ms}$. Recently, response of an ion mobility spectrometer to DMMP was compared to models derived from the work of Siegel and included the formation of proton bound dimer with reaction times of 10-100 $\mu$ s. ${ }^{53,56}$ Predicted and measured ion abundances were comparable until reaction times $>100 \mu$ s after which divergence occurred and was attributed to recombination reactions. Other models for glow discharge sources in mass spectrometry ${ }^{57}$ and for proton transfer reaction mass spectrometry ${ }^{44}$ are noteworthy yet limited for use in models here by differences in ionization chemistry.

Response using hydrated protons in an APCI MS instrument equipped with a corona discharge was quantitatively described where reaction times were established by the electric fields, gas flows, and distances between the ion source and vacuum interface. ${ }^{36}$ High sensitivity with rate constants of $2 \times 10^{-9} \mathrm{~cm}^{3}$ $\mathrm{s}^{-1}$ were observed for nitrogenous bases where a product ion was formed on every collision between $\mathrm{M}$ and $\mathrm{H}^{+}\left(\mathrm{H}_{2} \mathrm{O}\right)_{n}$. In contrast, not every collision between a hydrated proton and $\mathrm{M}$ forms a product ion with compounds of lesser gas phase basicity. This is seen in differing sensitivities (ion counts $\mathrm{s}^{-1} \mathrm{ppb}^{-1}$ ) in APCI MS which ranged from $10^{2}$ to $10^{3}$ for compounds with differences in gas phase basicity of $160 \mathrm{~kJ} / \mathrm{mol}$. Indeed, sensitivities for compounds with lesser gas phase basicity were increased with increased temperature. ${ }^{58}$ Such increases can be achieved also with decreased levels of moisture as shown recently with response or sensitivity for IMS. ${ }^{59,60}$ Finally, principles derived from reaction kinetics were used to enhance selectivity of APCI MS through extended reaction times with ultratrace vapor concentrations. ${ }^{61}$

Where models of APCI reactions have been provided, interests have been targeted by specific compounds, by precise applications for chemical measurements, ${ }^{62}$ or by design considerations for ion sources ${ }^{54}$ and models or computational tools have not been sufficiently general to explore broadly the sensitivity of reaction kinetics to various parameters. In this work, a model of APCI reactions has been developed and has been used to explore the impact of parameters on the rate of formation of protonated monomers and proton bound dimers for single substances. The goal in this work is to provide quantitative measures for APCI reactions with sufficient breath to inform the design and development of new sources for APCI MS and IMS and for analysis of response with existing sources and instrumentation.

\section{DESCRIPTION OF MODEL}

Details of Model. The model for APCI reactions is based on binary kinetics between hydrated protons and an analyte $(M)$ in air at or near ambient pressure with certain assumptions and limitations here:

1. Reactant ions, $\mathrm{H}^{+}\left(\mathrm{H}_{2} \mathrm{O}\right)_{n}$, are extracted from an ion source and mixed with sample vapor (M). There is no ion loss from recombination since there are no negative species in the reaction volume. The level of hydration $(n)$ and $\left[\mathrm{H}_{2} \mathrm{O}\right]$ are assumed constant.

2. Charge density for hydrated protons is fixed at an initial value and no further addition of charge is made during the reaction time. Computations are stopped when $\left[\mathrm{H}^{+}\left(\mathrm{H}_{2} \mathrm{O}\right)_{n}\right]$ or $[\mathrm{M}]=10^{-2} \mathrm{~cm}^{-3}$ for eq 1 and also when $\left[\mathrm{MH}^{+}\left(\mathrm{H}_{2} \mathrm{O}\right)_{x}\right]=10^{-2} \mathrm{~cm}^{-3}$ for eq 2 .

3. Losses from diffusion are included for ions in a cylindrical geometry of radius $r$ and height $(h)=2 r^{54}$

4. Moisture and temperature are "fixed" so the water cluster size $n$, in $\mathrm{H}^{+}\left(\mathrm{H}_{2} \mathrm{O}\right)_{n}$, is considered to be a weighted average between $\sim 2.5$ and 3.5 , consistent with rate constants reported by Bohme et al. ${ }^{63}$

5. There is no loss of ion density from dilution by gas flow or extraction of ions from the reaction volume.

6. Backward reactions are considered negligible. Once formed, a product ion lifetime exceeds the time scale of any experiment. That is $k_{\text {reverse }} \ll k_{\text {forward }}$ in eqs 1 and 2 .

7. Higher order ions such as proton bound trimers and tetramers are not considered due to short lifetimes.

8. Coulombic repulsions ${ }^{64}$ are not included in this model.

9. The model is general and suitable for use with aboveambient pressure where rate constants are increased significantly with increased pressure; ${ }^{65}$ thus, rate con- 
stants are higher than those sometimes seen in API conditions.

10. Recycling of $[\mathrm{M}]$ from diffusion-based neutralization of $\mathrm{M}_{2} \mathrm{H}^{+}\left(\mathrm{H}_{2} \mathrm{O}\right)_{z}$ was shown to be less than $1 \%$ for reaction times below $10 \mathrm{~ms}$ and was omitted.

11. The model did not include reactions between $\mathrm{H}^{+}\left(\mathrm{H}_{2} \mathrm{O}\right)_{n}$ and $2 \mathrm{M}$ or $\mathrm{M}_{2}$ since rate constants or ion lifetimes are unknown.

12. The compounds are assumed to be volatile and chemically stable with ranges of reactivities toward hydrated protons, and vapor concentrations are from sub-ppb to low $\mathrm{ppm}$ ranges.

Rate Equations. The rate of change in protonated monomer, or $\left[\mathrm{MH}^{+}\left(\mathrm{H}_{2} \mathrm{O}\right)_{x}\right]$, in eq 1 is described mathematically in eq 3 and simplified without recombination since this model is based on a unipolar condition (i.e., hydrated protons have been extracted from an ion source into a reaction volume free of negative charge). The model includes loss of ion density by ion diffusion and collision on surfaces of the reaction volume. The positive term in the right side of this equation refers to the rate at which $\mathrm{MH}^{+}\left(\mathrm{H}_{2} \mathrm{O}\right)_{x}$ ions are formed during the time interval $\mathrm{d} t$, whereas the negative expressions indicates the losses by sequential reactions, i.e. formation of proton bound dimer, or $\mathrm{M}_{2} \mathrm{H}^{+}\left(\mathrm{H}_{2} \mathrm{O}\right)_{z}$, and diffusion losses. Here, $k_{1}$ is the reaction rate constant of the reaction, $[\mathrm{M}]$ is the abundance of the neutral compound, $D_{+}$is the diffusion constant for positive ions over the diffusion length $\Lambda$.

$$
\begin{aligned}
& \frac{\mathrm{d}\left[\mathrm{MH}^{+}\left(\mathrm{H}_{2} \mathrm{O}\right)_{x}\right]}{\mathrm{d} t}=k_{1}[\mathrm{M}]\left[\mathrm{H}^{+}\left(\mathrm{H}_{2} \mathrm{O}\right)_{n}\right] \\
& -k_{2}[\mathrm{M}]\left[\mathrm{MH}^{+}\left(\mathrm{H}_{2} \mathrm{O}\right)_{x}\right]-\frac{D_{+}}{\Lambda^{2}}\left[\mathrm{MH}^{+}\left(\mathrm{H}_{2} \mathrm{O}\right)_{x}\right] \\
& \frac{\mathrm{d}\left[\mathrm{M}_{2} \mathrm{H}^{+}\left(\mathrm{H}_{2} \mathrm{O}\right)_{z}\right]}{\mathrm{d} t}=k_{2}[\mathrm{M}]\left[\mathrm{MH}^{+}\left(\mathrm{H}_{2} \mathrm{O}\right)_{x}\right] \\
& -\frac{D_{+}}{\Lambda^{2}}\left[\mathrm{M}_{2} \mathrm{H}^{+}\left(\mathrm{H}_{2} \mathrm{O}\right)_{z}\right] \\
& \frac{\mathrm{d}\left[\mathrm{H}^{+}\left(\mathrm{H}_{2} \mathrm{O}\right)_{n}\right]}{\mathrm{d} t}=-k_{1}[\mathrm{M}]\left[\mathrm{H}^{+}\left(\mathrm{H}_{2} \mathrm{O}\right)_{n}\right]-\frac{D_{+}}{\Lambda^{2}}\left[\mathrm{H}^{+}\left(\mathrm{H}_{2} \mathrm{O}\right)_{n}\right] \\
& \frac{\mathrm{d}[\mathrm{M}]}{\mathrm{d} t}=-k_{1}[\mathrm{M}]\left[\mathrm{H}^{+}\left(\mathrm{H}_{2} \mathrm{O}\right)_{n}\right]-k_{2}[\mathrm{M}]\left[\mathrm{MH}^{+}\left(\mathrm{H}_{2} \mathrm{O}\right)_{x}\right]
\end{aligned}
$$

Units in the computations differ from SI units in time and volume to match the familiar literature on ion molecule reaction kinetics. Time in $\mathrm{ms}$ or $\mu \mathrm{s}$ and volume in $\mathrm{cm}^{3}$ also match the parameters of experimental technology.

\section{EXPERIMENTAL SECTION}

Procedures. The sensitivities of ion formation and ion distributions to reaction parameters were explored using the model described above and six experiments are described in Table 1 with lists of parameters and links to graphics. Standard parameters or initial values were drawn broadly from experiences and reports of ion-molecule reactions. Unless noted, they were the following: $\left[\mathrm{H}^{+}\left(\mathrm{H}_{2} \mathrm{O}\right)_{n}\right]=1 \times 10^{10} \mathrm{~cm}^{-3}$ $(0.4 \mathrm{ppb}) ; k_{1}=1.0 \times 10^{-9} \mathrm{~cm}^{3} \mathrm{~s}^{-1} ; k_{2}=0.8 k_{1} ; 53=0.05 \mathrm{~cm}^{2}$ $\mathrm{s}^{-1},{ }^{4} \mathrm{r}=1.5 \mathrm{~cm} ; h=2 r$, and $[\mathrm{M}]=10 \mathrm{ppb}\left(2.46 \times 10^{11} \mathrm{~cm}^{-3}\right)$.

Reaction time is variable unless noted.

Experiment I.

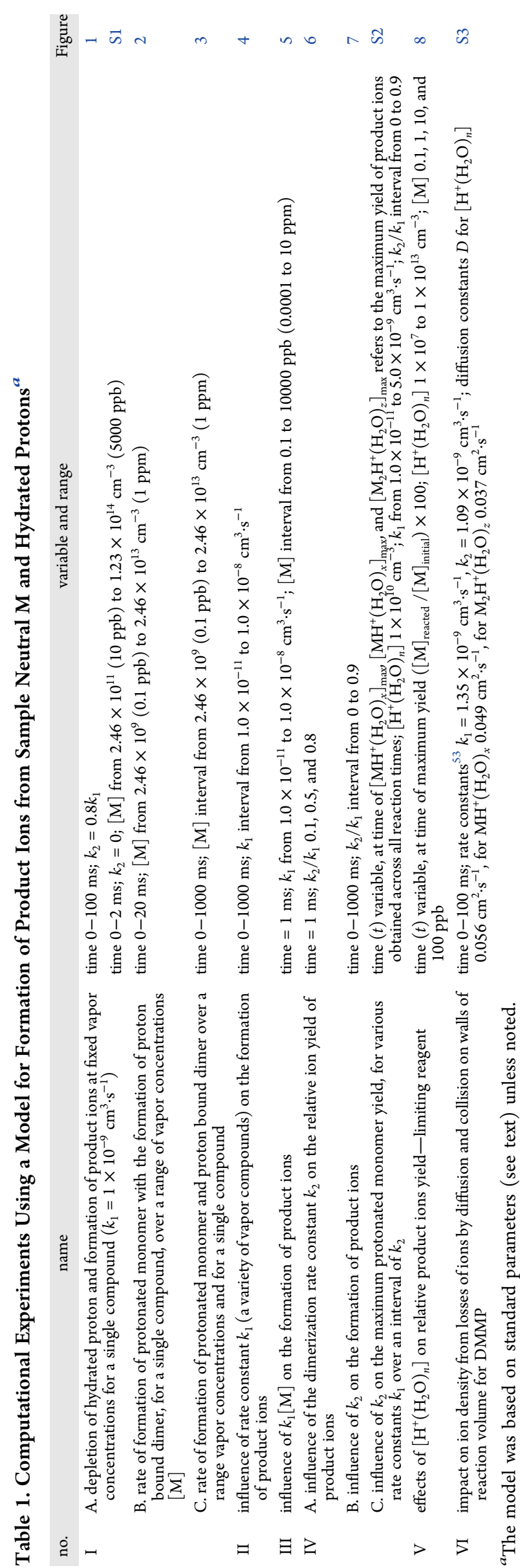


A. The depletion of $\left[\mathrm{H}^{+}\left(\mathrm{H}_{2} \mathrm{O}\right)_{n}\right]$ and the formation of product ions $\mathrm{MH}^{+}\left(\mathrm{H}_{2} \mathrm{O}\right)_{x}$ and $\mathrm{M}_{2} \mathrm{H}^{+}\left(\mathrm{H}_{2} \mathrm{O}\right)_{z}$, for a single compound reacting with a fixed $k_{1}$. Standard parameters were used with the model for a time step $<1 \mu$ s from 0 to $100 \mathrm{~ms}$. Plots were made in OriginLab for ion densities with time.

Only the formation of $\mathrm{MH}^{+}\left(\mathrm{H}_{2} \mathrm{O}\right)_{x}$ occurs: in this experiment, the sequential reaction to $\mathrm{M}_{2} \mathrm{H}^{+}\left(\mathrm{H}_{2} \mathrm{O}\right)_{z}$ was not included in the model $\left(k_{2}=0\right.$ in eqs 3,4 , and 6$)$ to show behavior for substances that do not form proton bound dimers. Standard parameters were used with a broad range of vapor concentrations for times from 0 to 2 ms.

B. The formation of $\mathrm{MH}^{+}\left(\mathrm{H}_{2} \mathrm{O}\right)_{x}$ and $\mathrm{M}_{2} \mathrm{H}^{+}\left(\mathrm{H}_{2} \mathrm{O}\right)_{z}$ for a specific substance $\left(k_{1}=1 \times 10^{-9} \mathrm{~cm}^{3} \mathrm{~s}^{-1}\right)$. In this experiment, the sequential reaction to $\mathrm{M}_{2} \mathrm{H}^{+}\left(\mathrm{H}_{2} \mathrm{O}\right)_{z}$ was included in the model $\left(k_{2}=0.8 k_{1}\right)$ in eqs 3,4 , and 6 . Five values for vapor concentration were considered: $0.1,1,10$, 100 , and $1000 \mathrm{ppb}$ and plots for ion yield are shown as a function of time.

C. The formation of product ions over an interval of vapor concentrations and time.

Experiment II. The formation of product ions over an interval of rate constants $k_{1}$ as a function time.

Experiment III. Four values of $k_{1}$ extracted from experiment II-C for line plots of ion yield at $1 \mathrm{~ms}$, as a function of an interval of $[\mathrm{M}]$.

\section{Experiment IV.}

A. The rate of formation of $\mathrm{MH}^{+}\left(\mathrm{H}_{2} \mathrm{O}\right)_{x} \mathrm{M}_{2} \mathrm{H}^{+}\left(\mathrm{H}_{2} \mathrm{O}\right)_{z}$ over a range of ratios for $k_{2} / k_{1}$ of $0.1,0.5$, and 0.8 for a fixed reaction time of $1 \mathrm{~ms}$ and an interval of $[\mathrm{M}]$.

B. The rate of formation of $\mathrm{MH}^{+}\left(\mathrm{H}_{2} \mathrm{O}\right)_{x}$ and $\mathrm{M}_{2} \mathrm{H}^{+}\left(\mathrm{H}_{2} \mathrm{O}\right)_{z}$ over an interval of $k_{2} / k_{1}$ ratios.

C. The monomer $\mathrm{MH}^{+}\left(\mathrm{H}_{2} \mathrm{O}\right)_{x}$ maximum yield as a function of an interval of $k_{2}$ for various compounds (i.e., $k_{1}$ ).

Experiment $V$. Influence of the reactant ion $\left[\mathrm{H}^{+}\left(\mathrm{H}_{2} \mathrm{O}\right)_{n}\right]$ on product ion yield and the effect of the limiting reagent on the distribution of $\left[\mathrm{MH}^{+}\left(\mathrm{H}_{2} \mathrm{O}\right)_{x}\right]$ and $\left[\mathrm{M}_{2} \mathrm{H}^{+}\left(\mathrm{H}_{2} \mathrm{O}\right)_{z}\right]$.

Experiment VI. The density of each ion species decreased by diffusion and collision on walls of the reaction volume. Loss of charge upon collision with a surface was modeled for dimethyl methylphosphonate (DMMP).

Computational Procedures. MatLab. The system of differential equations (eqs 3-6) was introduced into MatLab R2021a from MathWorks in order to find instantaneous analytic solutions. The latter were found from nested "for loops", for time and another varying parameter (i.e., $k_{1}, k_{2},[\mathrm{M}]$; see Table 1 ). For each value of the latter, the equations were solved for the entire time interval with a step size $\Delta t$, filling output arrays with instantaneous values. The time step size $\Delta t$ was chosen carefully (i.e., $\Delta t \ll 1 / k_{1}[\mathrm{M}]$ ) so that concentrations are not depleted rapidly in a few iterations, implicating unresolved solutions. Limiting reagents were taken into consideration: when one of the reactants is depleted, its consumption stops and so does the reaction. Only a limited number of elements was selected in time, as a sample from the output matrices of interest and exported in text files, to avoid graphics memory saturation when plotting contour plots. The reduced matrices were imported into OriginPro 2020 SR1 9.7.0.188, from OriginLab Corp. for plotting. MatLab files are accessible under the open access documentation (European Union's Horizon 2020 FET Open program under grant agreement no. 899261) at https://www. jottacloud.com/s/2616d6f1a4adba34e928097bc2be3e3e3f2.

\section{RESULTS AND DISCUSSION}

Vapor Concentration and Ion Distributions. The abundances of protonated monomer and proton bound dimer with a single neutral substance $(\mathrm{M})$ at a vapor concentration of $2.46 \times 10^{11} \mathrm{~cm}^{-3}$ (or $10 \mathrm{ppb}$ ) are shown in Figure 1 for reaction

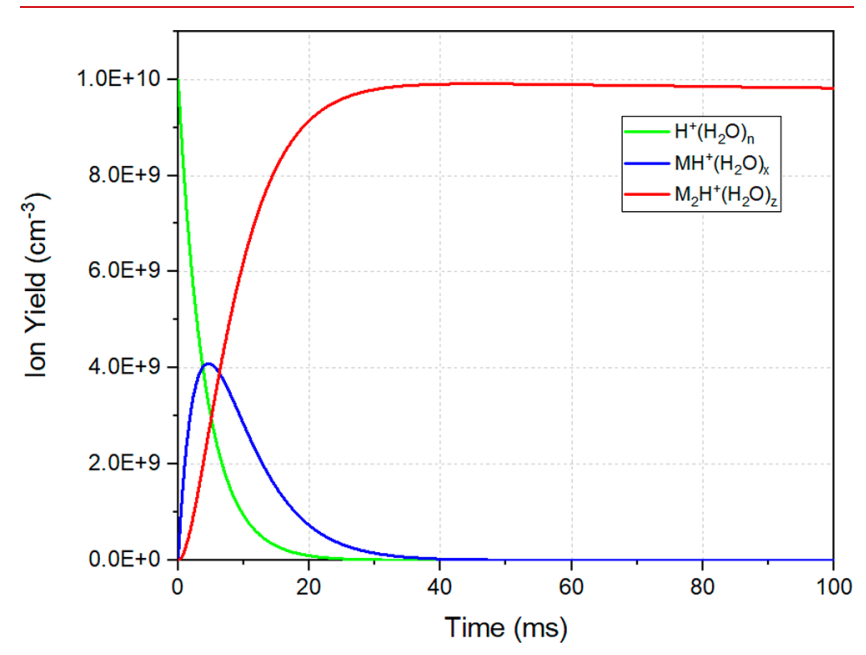

Figure 1. Time-dependent changes in ion densities for reaction of $\mathrm{M}$ with $\mathrm{H}^{+}\left(\mathrm{H}_{2} \mathrm{O}\right)_{n}$ for $[\mathrm{M}]=10 \mathrm{ppb}\left(=2.46 \times 10^{11} \mathrm{~cm}^{-3}\right)$.

times of $0-100 \mathrm{~ms}$ (experiment IA, Table 1). The plot for ion density of $\mathrm{H}^{+}\left(\mathrm{H}_{2} \mathrm{O}\right)_{n}$ follows eq 5 and is consistent with second order kinetics. The stepwise formation of product ions through eqs 1 and 2 can be seen in the increase in $\left[\mathrm{MH}^{+}\left(\mathrm{H}_{2} \mathrm{O}\right)_{x}\right]$ from $t=$ $0-4.5 \mathrm{~ms}$ and in the increase in $\left[\mathrm{M}_{2} \mathrm{H}^{+}\left(\mathrm{H}_{2} \mathrm{O}\right)_{z}\right]$ with concurrent decrease in $\left[\mathrm{MH}^{+}\left(\mathrm{H}_{2} \mathrm{O}\right)_{x}\right]$. The sequential nature of this reaction is seen also in the growth in intensity for $\mathrm{MH}^{+}\left(\mathrm{H}_{2} \mathrm{O}\right)_{x}$ and the slight lag by a few milliseconds in the appearance and an increase in intensity for $\mathrm{M}_{2} \mathrm{H}^{+}\left(\mathrm{H}_{2} \mathrm{O}\right)_{z}$.

After this time, $\left[\mathrm{M}_{2} \mathrm{H}^{+}\left(\mathrm{H}_{2} \mathrm{O}\right)_{z}\right]$ continues to increase until $\left[\mathrm{MH}^{+}\left(\mathrm{H}_{2} \mathrm{O}\right)_{x}\right]$ is depleted at $\sim 45 \mathrm{~ms}$ as $\left[\mathrm{H}^{+}\left(\mathrm{H}_{2} \mathrm{O}\right)_{n}\right]$ is depleted at $\sim 30 \mathrm{~ms}$. Since $\left[\mathrm{H}^{+}\left(\mathrm{H}_{2} \mathrm{O}\right)_{n}\right]$ was initially $1 \times 10^{10} \mathrm{~cm}^{-3}(\sim 0.4$ $\mathrm{ppb})$, there is an excess density of $2.26 \times 10^{11} \mathrm{~cm}^{-3}$ for $\left.\mathrm{M}\right)$ when the reaction has proceed entirely to $\left[\mathrm{M}_{2} \mathrm{H}^{+}\left(\mathrm{H}_{2} \mathrm{O}\right)_{z}\right]$; this constitutes a reaction yield for $\mathrm{M}$ of only $8.11 \%$. A gradual decrease in $\left[\mathrm{M}_{2} \mathrm{H}^{+}\left(\mathrm{H}_{2} \mathrm{O}\right)_{z}\right]$ between 40 to $60 \mathrm{~ms}$ arises from ion diffusion and collisions on surfaces of the reaction volume under quiescent flow condition exclusive of Coulombic repulsions. ${ }^{64,66}$

Reaction times to reach maximum $\left[\mathrm{MH}^{+}\left(\mathrm{H}_{2} \mathrm{O}\right)_{x}\right]$ were dependent on the concentration of $\mathrm{M}$ and some representative values were the following: $45.3 \mu \mathrm{s}$ for $2.46 \times 10^{13} \mathrm{~cm}^{-3}(1000$ $\mathrm{ppb})$; $90.6 \mu \mathrm{s}$ for $1.23 \times 10^{13} \mathrm{~cm}^{-3}$ (500 ppb); $454 \mu \mathrm{s}$ for $2.46 \times$ $10^{12} \mathrm{~cm}^{-3}$ (100 ppb); $909 \mu \mathrm{s}$ for $1.23 \times 10^{12} \mathrm{~cm}^{-3}$ (50 ppb); and $4.62 \mathrm{~ms}$ for $2.46 \times 10^{11} \mathrm{~cm}^{-3}(10 \mathrm{ppb})$ (see Table 2). This dependence is also shown partially in Figure 2 for reaction times under $20 \mathrm{~ms}$.

Where reactions form proton bound dimers, reaction times to full response or maximum $\left[\mathrm{M}_{2} \mathrm{H}^{+}\left(\mathrm{H}_{2} \mathrm{O}\right)_{z}\right]$ are shown in Table 2 and seen in Figure 2 (dashed lines). They could reach times of $45.63 \mathrm{~ms}$ for $[\mathrm{M}]=10 \mathrm{ppb}$, also with unreacted $\mathrm{M}$, e.g., $91.89 \%$ excess at $10 \mathrm{ppb}$ to $99.99 \%$ excess $10 \mathrm{ppm}$ (Table 2). A complete description for ion distributions, reaction times, and vapor concentrations is shown as a contour plot in Figure 3 and encompasses parameters of modern APCI MS and IMS 
Table 2. Metrics for Reaction of $M$ with $\mathrm{H}^{+}\left(\mathrm{H}_{2} \mathrm{O}\right)_{n}$ Leading to Formation of $\mathrm{MH}^{+}\left(\mathrm{H}_{2} \mathrm{O}\right)_{x}$ and $\mathrm{M}_{2} \mathrm{H}^{+}\left(\mathrm{H}_{2} \mathrm{O}\right)_{z}{ }^{a}$

\begin{tabular}{|c|c|c|c|c|c|c|c|c|}
\hline $\begin{array}{l}{[\mathrm{M}]} \\
\mathrm{ppm}\end{array}$ & $\begin{array}{l}{\left[\mathrm{MH}^{+}\left(\mathrm{H}_{2} \mathrm{O}\right)_{x}\right]} \\
\mathrm{cm}^{-3}\left(\times 10^{9}\right)\end{array}$ & $\begin{array}{c}{\left[\mathrm{MH}^{+}\left(\mathrm{H}_{2} \mathrm{O}\right)_{x}\right]_{\text {max }} /} \\
{\left[\mathrm{H}^{+}\left(\mathrm{H}_{2} \mathrm{O}\right)_{n}\right]_{\text {initial }}}\end{array}$ & $\begin{array}{c}\text { time to } \\
{\left[\mathrm{MH}^{+}\left(\mathrm{H}_{2} \mathrm{O}\right)_{\mathrm{x}}\right]_{\max }} \\
\mathrm{ms}\end{array}$ & $\begin{array}{c}{\left[\mathrm{M}_{2} \mathrm{H}^{+}\left(\mathrm{H}_{2} \mathrm{O}\right)_{9}\right]} \\
\mathrm{cm}^{-3}\left(\times 10^{9}\right)\end{array}$ & $\begin{array}{c}{\left[\mathrm{M}_{2} \mathrm{H}^{+}\left(\mathrm{H}_{2} \mathrm{O}\right)_{2}\right]_{\max } /} \\
{\left[\mathrm{H}^{+}\left(\mathrm{H}_{2} \mathrm{O}\right)_{n}\right]_{\text {initial }}}\end{array}$ & $\begin{array}{c}\text { time to } \\
{\left[\mathrm{M}_{2} \mathrm{H}^{+}\left(\mathrm{H}_{2} \mathrm{O}\right)_{2}\right]_{\max }} \\
\mathrm{ms}\end{array}$ & $\begin{array}{c}\text { unreacted } \\
{[\mathrm{M}] \mathrm{cm}^{-3}} \\
\left.10^{14}\right)\end{array}$ & $\%$ unreacted $\mathrm{M}$ \\
\hline 0.01 & 4.0925 & 0.40925 & 4.6183 & 9.9064 & 0.99064 & 45.627 & 0.0022643 & 91.892 \\
\hline 0.05 & 4.0953 & 0.40953 & 0.90913 & 9.9790 & 0.99790 & 10.394 & 0.012120 & 98.375 \\
\hline 0.1 & 4.0957 & 0.40957 & 0.45368 & 9.9889 & 0.99889 & 5.5257 & 0.024441 & 99.187 \\
\hline 0.5 & 4.0962 & 0.40962 & 0.090590 & 9.9975 & 0.99975 & 1.2654 & 0.12300 & 99.836 \\
\hline 1 & 4.0964 & 0.40964 & 0.045280 & 9.9987 & 0.99987 & 0.66782 & 0.24621 & 99.917 \\
\hline 5 & 4.0983 & 0.40982 & 0.0090500 & 9.9997 & 0.99997 & 0.14990 & 1.2318 & 99.982 \\
\hline 10 & 4.1005 & 0.41005 & 0.0045200 & 9.9999 & 0.99998 & 0.078440 & 2.4639 & 99.990 \\
\hline
\end{tabular}

${ }^{a}$ Values for $[\mathrm{M}]$ in $\mathrm{cm}^{-3}$ are shown in Table 3. Comments on significant figures are found in Supporting Information.

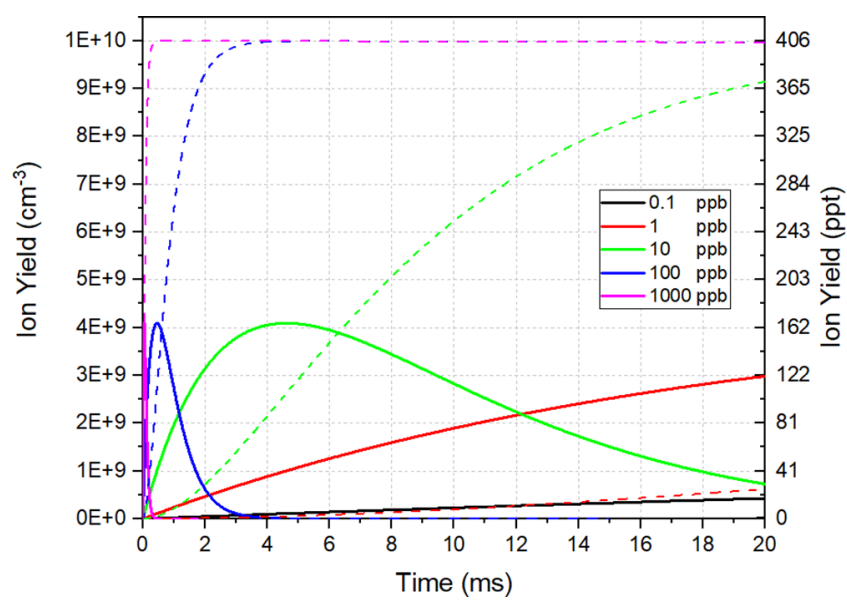

Figure 2. Time-dependent changes for $\left[\mathrm{MH}^{+}\left(\mathrm{H}_{2} \mathrm{O}\right)_{x}\right]$ (solid lines) and $\left[\mathrm{M}_{2} \mathrm{H}^{+}\left(\mathrm{H}_{2} \mathrm{O}\right)_{z}\right]$ (dashed lines), at five vapor concentrations of $\mathrm{M}$.

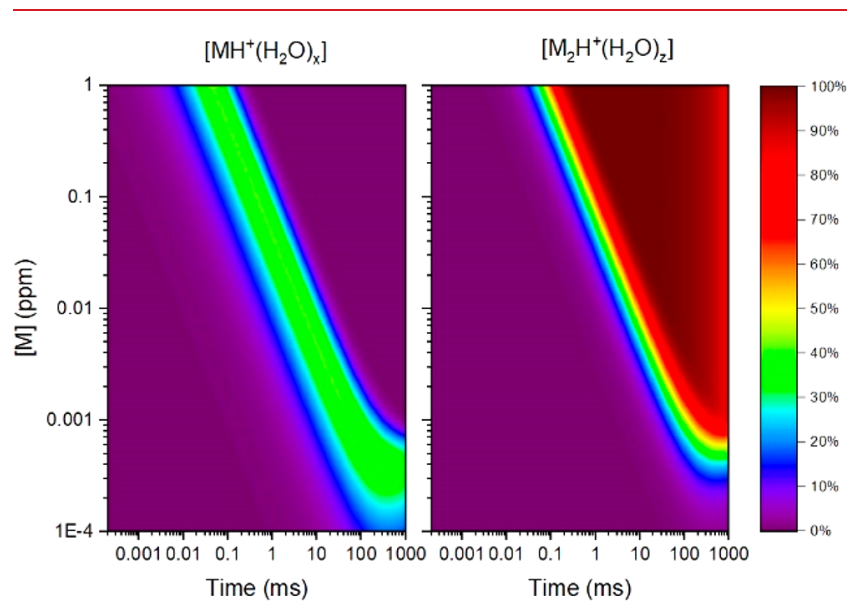

Figure 3. Contour plots of $\left.\left[\mathrm{MH}^{+}\left(\mathrm{H}_{2} \mathrm{O}\right)_{x}\right)\right]$ and $\left.\left[\mathrm{M}_{2} \mathrm{H}^{+}\left(\mathrm{H}_{2} \mathrm{O}\right)_{z}\right)\right]$ in percent of initial $\left[\mathrm{H}^{+}\left(\mathrm{H}_{2} \mathrm{O}\right)_{n}\right]$, vapor concentration, and reaction time under standard conditions of the model.

measurements. The plots show that reaction times for maximum yield of $\mathrm{MH}^{+}\left(\mathrm{H}_{2} \mathrm{O}\right)_{x}$ are dependent on vapor concentration and that $\mathrm{MH}^{+}\left(\mathrm{H}_{2} \mathrm{O}\right)_{x}$ is depleted by $\mathrm{M}_{2} \mathrm{H}^{+}\left(\mathrm{H}_{2} \mathrm{O}\right)_{z}$ uniformly across all [M], except at 100 to $300 \mathrm{ppt}$, where $\mathrm{M}$ is the limiting reagent. In this region, the limiting reagent is $\mathrm{M}$ and only $\mathrm{H}^{+}\left(\mathrm{H}_{2} \mathrm{O}\right)_{n}$ and $\mathrm{MH}^{+}\left(\mathrm{H}_{2} \mathrm{O}\right)_{x}$ are visible at this scaling. The protonated monomer reaches maximum ion density at times from 0.1 to $>100 \mathrm{~ms}$ for $[\mathrm{M}]$ from $1 \mathrm{ppm}$ to $0.1 \mathrm{ppb}$, respectively.

The scale for reaction yield shows that a maximum near $40 \%$ (in percent of initial $\left[\mathrm{H}^{+}\left(\mathrm{H}_{2} \mathrm{O}\right)_{n}\right]$, Figures 2 and 3) for
$\mathrm{MH}^{+}\left(\mathrm{H}_{2} \mathrm{O}\right)_{x}$ is reached (referenced to initial $\left[\mathrm{H}^{+}\left(\mathrm{H}_{2} \mathrm{O}\right)_{n}\right]$ ), regardless of vapor concentration and reaction time.

In summary, reaction time scales for vapor concentrations of analytes, as found in IMS and API MS studies with low ppb to low ppm, occur at times from low microseconds to tens of milliseconds and are governed significantly by the onward reaction to form protonated monomers by $k_{1}$ and proton bound dimers by $k_{2}$. In the discussion above, $k_{1}$ was fixed at a relatively high value as found with compounds with favorable response such as amines or organophosphorus compounds and $k_{2}$ was fixed against $k_{1}{ }^{67}$ Differences in rate constants should also influence reaction kinetics both in time scales and in the quantitative abundances of ions.

Rates Constants and Ion Distributions. The favorability of reaction chemistry with hydrated protons is based on the strength of the dipole-ion association of $\mathrm{M} \cdots \cdot \mathrm{H}^{+}$and is described by reaction enthalpies. In reaction rates, the differences in "reactivity" are reflected in the magnitude of rate constants and these can range from $1 \times 10^{-11} \mathrm{~cm}^{3} \mathrm{~s}^{-1}$ for weakly reactive substances such as alkenes to $\sim 7 \times 10^{-9} \mathrm{~cm}^{3} \mathrm{~s}^{-1}$ for strongly reactive substances such as amines. The influence of $k_{1}$ is shown in Figure 4 as contour plots for reaction yield, $k_{1}$, and

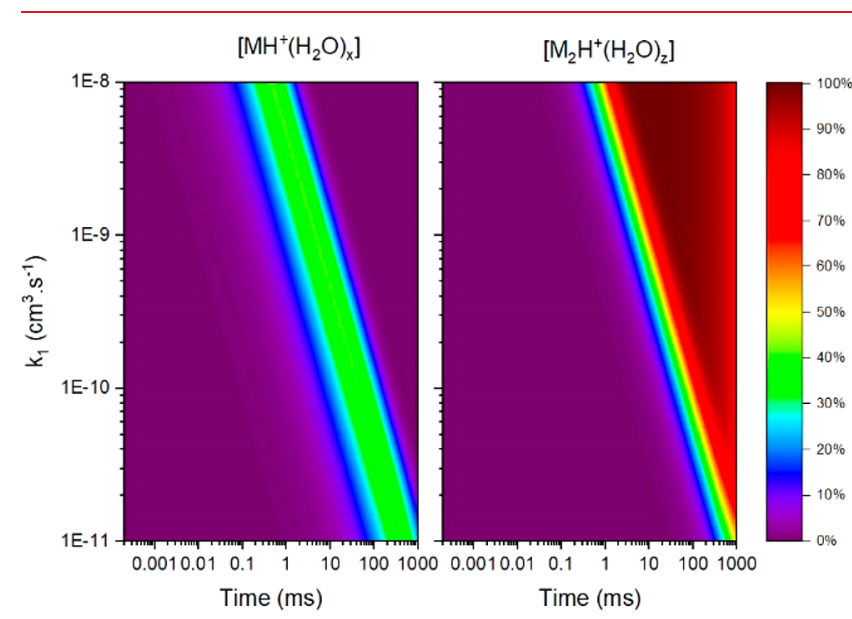

Figure 4. Contour plots of $\mathrm{MH}^{+}\left(\mathrm{H}_{2} \mathrm{O}\right)_{x}$ and $\mathrm{M}_{2} \mathrm{H}^{+}\left(\mathrm{H}_{2} \mathrm{O}\right)_{z}$ abundances (in percent), rate constant $k_{1}$, and time under standard conditions of the model.

reaction time. Calculations show the impact of $k_{1}$ in the time to depletion of $\mathrm{H}^{+}\left(\mathrm{H}_{2} \mathrm{O}\right)_{n}$. This occurs at $1 \mathrm{~ms}$ reaction time at 20 $\mathrm{ppb}$ for a "reactive" compound with $k_{1}$ of $1 \times 10^{-8} \mathrm{~cm}^{3} \mathrm{~s}^{-1}$ and in contrast will occur at $2 \mathrm{ppm}$ for an "unreactive" compound with $k_{1}$ of $1 \times 10^{-10} \mathrm{~cm}^{3} \mathrm{~s}^{-1}$ (Figure 5).

The results are consistent with $k_{1}[\mathrm{M}]\left[\mathrm{H}^{+}\left(\mathrm{H}_{2} \mathrm{O}\right)_{n}\right]$ through eq 3. At fixed reaction times ( $1 \mathrm{~ms}$ in Figure 5$)$, the maximum 


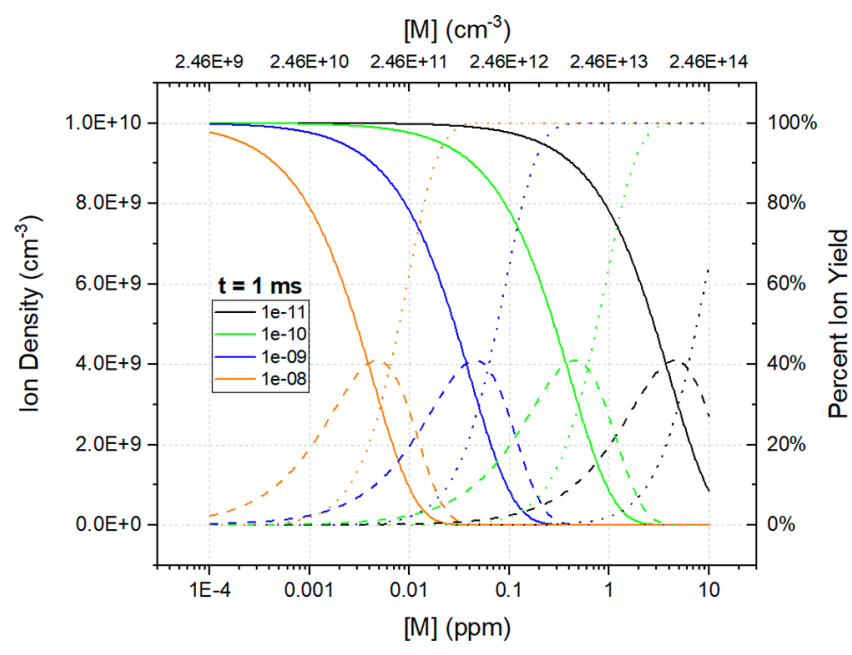

Figure 5. Sensitivity of ion abundances to $k_{1} \times[\mathrm{M}]$ at $t=1 \mathrm{~ms}$. Plots are shown for four values of $k_{1}$ (color code in legend): (solid lines) $\left[\mathrm{H}^{+}\left(\mathrm{H}_{2} \mathrm{O}\right)_{n}\right] ;$ (dashed lines) $\left[\mathrm{MH}^{+}\left(\mathrm{H}_{2} \mathrm{O}\right)_{x}\right]$; (dotted lines) $\left[\mathrm{M}_{2} \mathrm{H}^{+}\left(\mathrm{H}_{2} \mathrm{O}\right)_{z}\right]$.

percent yield for $\mathrm{MH}^{+}\left(\mathrm{H}_{2} \mathrm{O}\right)_{x}$ is $\sim 40 \%$ from the product of $k_{1} \backslash[\mathrm{M}]$ over a range of $[\mathrm{M}]$ and values for $k_{1}$. An increase in $[\mathrm{M}]$ would shift the maximum yield for $\mathrm{MH}^{+}\left(\mathrm{H}_{2} \mathrm{O}\right)_{x}$ toward reaction times $<1 \mathrm{~ms}$ (and vice versa) (Figure 3 ). This explains the drop in the protonated monomer yield at $1 \mathrm{~ms}$ for increasing [M].

Results in Figure 4 and 5 show quantitatively that maximum yield of protonated monomer spans a range of $k_{1}[\mathrm{M}]$ and reaction times, although $k_{2}$ is also expected control product ion distributions.

In Figure 6, distributions of $\left[\mathrm{MH}^{+}\left(\mathrm{H}_{2} \mathrm{O}\right)_{x}\right]_{\max }$ and $\left[\mathrm{M}_{2} \mathrm{H}^{+}\left(\mathrm{H}_{2} \mathrm{O}\right)_{z}\right]_{\max }$ are shown for $1 \mathrm{~ms}$ reaction time, over a

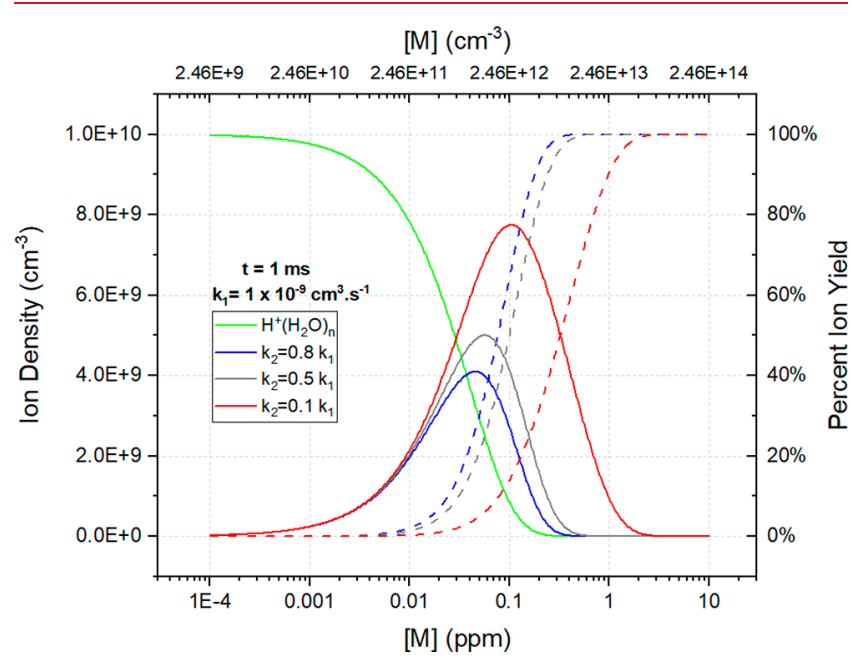

Figure 6. Sensitivity of ion abundances to $k_{2} / k_{1}$ (color code in legend): (solid lines) $\left[\mathrm{H}^{+}\left(\mathrm{H}_{2} \mathrm{O}\right)_{n}\right]$ and $\left[\mathrm{MH}^{+}\left(\mathrm{H}_{2} \mathrm{O}\right)_{x}\right] ;$ (dashed lines) $\left[\mathrm{M}_{2} \mathrm{H}^{+}\left(\mathrm{H}_{2} \mathrm{O}\right)_{z}\right]$.

range of $[\mathrm{M}]$ and ratio of $k_{2} / k_{1}$ where $k_{1}$ is fixed. The maximum yield for the protonated monomer, $\left[\mathrm{MH}^{+}\left(\mathrm{H}_{2} \mathrm{O}\right)_{x}\right]_{\max }$ is dependent on $k_{2}$ with characteristic values for $[\mathrm{M}]$ and reaches near $80 \%$ of $\left[\mathrm{H}^{+}\left(\mathrm{H}_{2} \mathrm{O}\right)_{n}\right]_{\text {initial }}$ when $k_{2}$ is $0.1 k_{1}$.

In Figure 7, these behaviors are shown for $[\mathrm{M}]$ at $10 \mathrm{ppb}$ with an increased range in the ratio $k_{2} / k_{1}$. The protonated monomer rises, for $k_{2} / k_{1}=0.8$, above $20 \%$ from $\sim 1$ to $20 \mathrm{~ms}$ with a

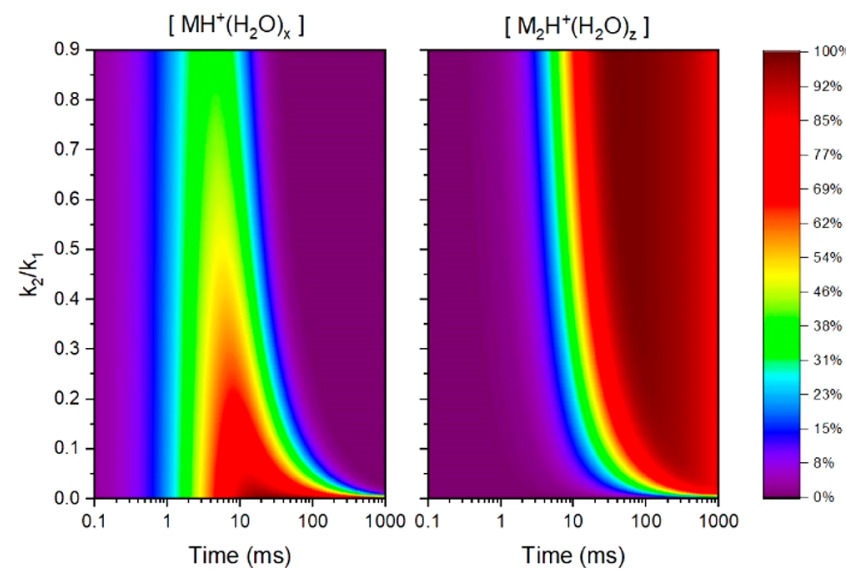

Figure 7. Contour plots of $\left[\mathrm{MH}^{+}\left(\mathrm{H}_{2} \mathrm{O}\right)_{x}\right]$ and $\left[\mathrm{M}_{2} \mathrm{H}^{+}\left(\mathrm{H}_{2} \mathrm{O}\right)_{z}\right]$ (in percent), ratio $k_{2} / k_{1}$, and reaction time, at standard conditions of the model.

maximum yield $\sim 40 \%$ near $4 \mathrm{~ms}$. The maximum yield of $\sim 20 \%$ (at $1 \mathrm{~ms}$ ) is clearly seen in Figure 6 (blue dashed line at $10 \mathrm{ppb}$ ).

In contrast, a timespan of $1 \mathrm{~ms}$ to nearly $80 \mathrm{~ms}$ was obtained for $k_{2} / k_{1}=0.1$, where $\left[\mathrm{MH}^{+}\left(\mathrm{H}_{2} \mathrm{O}\right)_{x}\right]>20 \%$. This ratio would be characteristic of substances with low tendency to form a proton bound dimer. In addition, reaction yield for $\left.\left[\mathrm{MH}^{+}\left(\mathrm{H}_{2} \mathrm{O}\right)_{x}\right)\right]$ will be elevated for compounds with weak reactivity for $k_{2}$ and will exceed the $40 \%$ noted above. When formation of proton bound dimer is particularly slow, reaction yield for $\left.\left[\mathrm{MH}^{+}\left(\mathrm{H}_{2} \mathrm{O}\right)_{x}\right)\right]$. could reach more than $90 \%$ (Figure S2).

Limiting Reagent, $\left.\left[\mathrm{H}^{+}\left(\mathrm{H}_{2} \mathrm{O}\right)_{n}\right)\right]$, and Relative Product Ion Yield. In all studies described above, $\left.\left[\mathrm{H}^{+}\left(\mathrm{H}_{2} \mathrm{O}\right)_{n}\right)\right]$ was the limiting reagent where excess unreacted $\mathrm{M}$ ranged from 95 to 99.99\% (Table 3), depending on [M] and $k_{1}$. Certain aspects of ion distributions are seemingly independent of $\left.\left[\mathrm{H}^{+}\left(\mathrm{H}_{2} \mathrm{O}\right)_{n}\right)\right]$; for example, in the regime where $\mathrm{H}^{+}\left(\mathrm{H}_{2} \mathrm{O}\right)_{n}$ is the limiting reagent $\left(\left[\mathrm{H}^{+}\left(\mathrm{H}_{2} \mathrm{O}\right)_{n}\right]<[\mathrm{M}]\right)$, the ratio of $\left[\mathrm{MH}^{+}\left(\mathrm{H}_{2} \mathrm{O}\right)_{x}\right]_{\max } /$ $\left[\mathrm{M}_{2} \mathrm{H}^{+}\left(\mathrm{H}_{2} \mathrm{O}\right)_{z}\right]_{\max }$ is nearly constant over the range of $\left[\mathrm{H}^{+}\left(\mathrm{H}_{2} \mathrm{O}\right)_{n}\right]$ (Figure 8). In principle, excessive levels of $\mathrm{H}^{+}\left(\mathrm{H}_{2} \mathrm{O}\right)_{n}$ could be introduced into the reaction volume where $\mathrm{M}$ becomes the limiting reagent.

In Figure 8, the effect of $\left.\left[\mathrm{H}^{+}\left(\mathrm{H}_{2} \mathrm{O}\right)_{n}\right)\right]$ is shown for timeindependent maximum product ion yield, for a range of $[\mathrm{M}]$ with standard conditions of the model. When $[\mathrm{M}]=0.1 \mathrm{ppb}$, $\left[\mathrm{MH}^{+}\left(\mathrm{H}_{2} \mathrm{O}\right)_{x}\right]_{\max }$ and $\left[\mathrm{M}_{2} \mathrm{H}^{+}\left(\mathrm{H}_{2} \mathrm{O}\right)_{z}\right]_{\max }$ increase proportionally with increased $\left.\left[\mathrm{H}^{+}\left(\mathrm{H}_{2} \mathrm{O}\right)_{n}\right)\right]$, from $1 \times 10^{7}$ to $1 \times 10^{9} \mathrm{~cm}^{-3}$.

At even higher levels of $\left.\left[\mathrm{H}^{+}\left(\mathrm{H}_{2} \mathrm{O}\right)_{n}\right)\right],\left[\mathrm{MH}^{+}\left(\mathrm{H}_{2} \mathrm{O}\right)_{x}\right]_{\max }$ continues to increase proportionally while $\left[\mathrm{M}_{2} \mathrm{H}^{+}\left(\mathrm{H}_{2} \mathrm{O}\right)_{z}\right]_{\max }$ decreases. Eventually, $\left[\mathrm{MH}^{+}\left(\mathrm{H}_{2} \mathrm{O}\right)_{x}\right]_{\max }$ cannot increase indefinitely with $\left.\left[\mathrm{H}^{+}\left(\mathrm{H}_{2} \mathrm{O}\right)_{n}\right)\right]$ and reaches a plateau at a density very close to that of $[\mathrm{M}]$. The decrease of $\left[\mathrm{M}_{2} \mathrm{H}^{+}\left(\mathrm{H}_{2} \mathrm{O}\right)_{z}\right]_{\max }$ arises from $k_{1}>k_{2}$, and the rapid consumption of $[\mathrm{M}]$ in producing $\mathrm{MH}^{+}\left(\mathrm{H}_{2} \mathrm{O}\right)_{x}$, thus suppresses the formation of proton bound dimer via $k_{2}\left[\mathrm{MH}^{+}\left(\mathrm{H}_{2} \mathrm{O}\right)_{x}\right][\mathrm{M}]$.

Diffusion Losses. Ion density for proton bound dimers in Figures 3, 4, and 7 all exhibit a noticeable loss with reaction times $>200 \mathrm{~ms}$, exhibited by the fading of the red color. This loss occurs through ion collisions on walls of the reaction volume, resulting in neutralization and decreases in $\left[\mathrm{M}_{2} \mathrm{H}^{+}\left(\mathrm{H}_{2} \mathrm{O}\right)_{z}\right]$. Findings from experiment VI are shown in Figure S3 where radii of reaction volumes were $0.5-2 \mathrm{~cm}^{54}$ and height was $2 r$. Under these conditions, diffusion losses for DMMP increase with decreasing volume (radii) and are below $1 \%$ for time intervals $<5$ $\mathrm{ms}$, even for the smallest selected radius $(r=0.5 \mathrm{~cm})$. Another 
Table 3. Metrics for Reaction of $\mathrm{M}$ with $\mathrm{H}^{+}\left(\mathrm{H}_{2} \mathrm{O}\right)_{n}$ Leading to Formation of $\mathrm{MH}^{+}\left(\mathrm{H}_{2} \mathrm{O}\right)_{x}$ without Formation of Proton Bound Dimer $\left(k_{2}=0\right)$

\begin{tabular}{|c|c|c|c|c|c|c|}
\hline $\begin{array}{l}{[\mathrm{M}]} \\
\mathrm{ppm}\end{array}$ & $\underset{\left.10^{14}\right)}{[\mathrm{M}] \mathrm{cm}^{-3}}(\times$ & $\underset{\left.10^{9}\right)}{\left[\mathrm{MH}^{+}\left(\mathrm{H}_{2} \mathrm{O}\right)_{\mathrm{xax}}\right]_{\max } \mathrm{cm}^{-3}(\times}$ & $\begin{array}{c}{\left[\mathrm{MH}^{+}\left(\mathrm{H}_{2} \mathrm{O}\right)_{\mathrm{x}}\right]_{\max } /} \\
{\left[\mathrm{H}^{+}\left(\mathrm{H}_{2} \mathrm{O}\right)_{n}\right]_{\text {initial }}}\end{array}$ & $\begin{array}{l}\text { time to maximum yield } \\
\mathrm{ms}\end{array}$ & $\begin{array}{c}\text { unreacted }[\mathrm{M}] \mathrm{cm}^{-3}(\times \\
\left.10^{14}\right)\end{array}$ & $\%$ unreacted $\mathrm{M}$ \\
\hline 0.01 & 0.0024641 & 9.93721 & 0.99372 & 30.122 & 0.0023641 & 95.943 \\
\hline 0.05 & 0.012321 & 9.98531 & 0.99853 & 7.1983 & 0.012220 & 99.187 \\
\hline 0.1 & 0.024641 & 9.99216 & 0.99922 & 3.8702 & 0.024540 & 99.592 \\
\hline 0.5 & 0.12321 & 9.99820 & 0.99982 & 0.90275 & 0.12310 & 99.917 \\
\hline 1 & 0.24641 & 9.99905 & 0.99990 & 0.47934 & 0.24630 & 99.957 \\
\hline 5 & 1.2321 & 9.99979 & 0.99998 & 0.10885 & 1.2319 & 99.990 \\
\hline 10 & 2.4641 & 9.99989 & 0.99999 & 0.057200 & 2.4639 & 99.994 \\
\hline
\end{tabular}

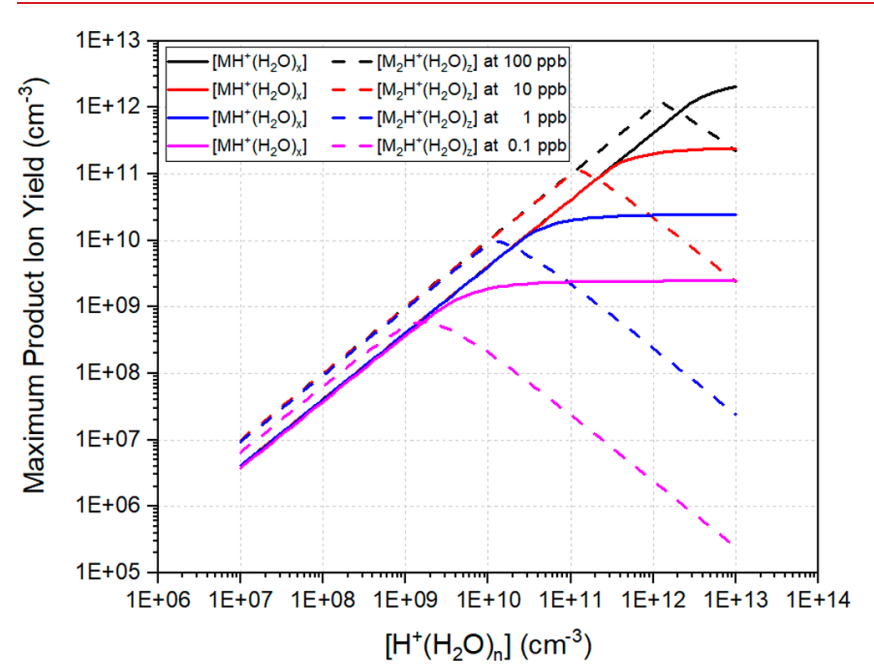

Figure 8. Influence of $\left[\mathrm{H}^{+}\left(\mathrm{H}_{2} \mathrm{O}\right)_{n}\right]$ on maximum product ion yield for four concentrations of $[\mathrm{M}]\left(100 \mathrm{ppb}=2.46 \times 10^{12} \mathrm{~cm}^{-3}, 10 \mathrm{ppb}=2.46\right.$ $\times 10^{11} \mathrm{~cm}^{-3}, 1 \mathrm{ppb}=2.46 \times 10^{10} \mathrm{~cm}^{-3}$, and $\left.0.1 \mathrm{ppb}=2.46 \times 10^{9} \mathrm{~cm}^{-3}\right)$ : (solid lines) $\left[\mathrm{MH}^{+}\left(\mathrm{H}_{2} \mathrm{O}\right)_{x}\right]$; (dashed lines) $\left[\mathrm{M}_{2} \mathrm{H}^{+}\left(\mathrm{H}_{2} \mathrm{O}\right)_{z}\right]$.

parameter that may affect diffusion losses is the diffusion rate constant that is dependent on the ionized compound and the electric field environment. In the literature, ${ }^{54}$ a value of $D=0.05$ $\mathrm{cm}^{2} \mathrm{~s}^{-1}$ has been used. In the case of experiment VI, diffusion constants for the DMMP monomer and dimer were derived from reduced mobility coefficients using the Nernst-Einstein equation. ${ }^{68}$ The findings demonstrate the validity of assumption 10.

\section{CONCLUSIONS}

Models of reactions of hydrated protons with an analyte (M) provide reaction times, ion distributions, and maximum reaction yields for a range of parameters common to APCI MS and IMS measurements. These models are sufficiently general to permit refinement or adaptation for specific conditions which may be found in various ion sources operated at or near ambient pressure in mass spectrometry. Models here disclose the sensitivity of ion distributions in time, particularly to the product $k_{1}[\mathrm{M}]$, the ratio $k_{2} / k_{1}$, and to the introduction of hydrated protons as excess reagent. Consequently, these models may provide a foundation and tools for the development of new technologies or methodologies for ion processing in analytical measurements, based on reaction kinetics, including the separation of ion mixtures. ${ }^{69}$

\section{ASSOCIATED CONTENT}

\section{Supporting Information}

The Supporting Information is available free of charge at https://pubs.acs.org/doi/10.1021/jasms.1c00158.

Comments on significant figures and Figures S1-S3 (PDF)

\section{AUTHOR INFORMATION}

\section{Corresponding Author}

Elie Lattouf - VERIFIN, Finnish Institute for Verification of the Chemical Weapons Convention, Department of Chemistry, University of Helsinki, FI-00014 Helsinki, Finland; Email: elie.lattouf@helsinki.fi

\section{Authors}

Osmo Anttalainen - VERIFIN, Finnish Institute for Verification of the Chemical Weapons Convention, Department of Chemistry, University of Helsinki, FI-00014 Helsinki, Finland

Tapio Kotiaho - Drug Research Program and Division of Pharmaceutical Chemistry and Technology, Faculty of Pharmacy, University of Helsinki, FI-00014 Helsinki, Finland; Department of Chemistry, Faculty of Science, University of Helsinki, FIN-00014 Helsinki, Finland; (i) orcid.org/00000003-0382-8578

Hanna Hakulinen - VERIFIN, Finnish Institute for Verification of the Chemical Weapons Convention, Department of Chemistry, University of Helsinki, FI-00014 Helsinki, Finland

Paula Vanninen - VERIFIN, Finnish Institute for Verification of the Chemical Weapons Convention, Department of Chemistry, University of Helsinki, FI-00014 Helsinki, Finland

Gary Eiceman - VERIFIN, Finnish Institute for Verification of the Chemical Weapons Convention, Department of Chemistry, University of Helsinki, FI-00014 Helsinki, Finland; Department of Chemistry and Biochemistry, New Mexico State University, Las Cruces, New Mexico 88003, United States; (1) orcid.org/0000-0001-9026-7208

Complete contact information is available at: https://pubs.acs.org/10.1021/jasms.1c00158

\section{Author Contributions}

The authors confirm contributions to the paper as follows: modeling, programming, graphics, E.L.; assistance on computation, O.A.; data interpretation, E.L. and G.E.; manuscript preparation, E.L., T.K., and G.E.; results review, H.H. and P.V. All of the authors reviewed the results and approved the final version of the manuscript. 


\section{Notes}

The authors declare no competing financial interest.

\section{ACKNOWLEDGMENTS}

This project, Gas Ion Distillation and Sequential Ion Processing Technologies for Identification and Visualization of Chemicals in Airborne Vapours, has received funding from the European Union's Horizon 2020 FET Open program under grant agreement no. 899261.

\section{REFERENCES}

(1) Horning, E. C.; Horning, M. G.; Carroll, D. I.; Dzidic, I.; Stillwell, R. N. New Picogram Detection System Based on a Mass Spectrometer with an External Ionization Source at Atmospheric Pressure. Anal. Chem. 1973, 45 (6), 936-943.

(2) Tarr, M. A.; Zhu, J.; Cole, B. Atmospheric Pressure Ionization Mass Spectrometry. Encycl. Anal. Chem. 2000, 1-34.

(3) Bruins, A. P. Atmospheric-Pressure-Ionization Mass Spectrometry. I. Instrumentation and Ionization Techniques. TrAC, Trends Anal. Chem. 1994, 13 (1), 37-43.

(4) Bruins, A. P. Atmospheric-Pressure-Ionization Mass Spectrometry. II. Applications in Pharmacy, Biochemistry and General Chemistry. TrAC, Trends Anal. Chem. 1994, 13 (2), 81-90.

(5) Proctor, C. J.; Todd, J. F. J. Alternative Reagent Ions for Plasma Chromatography. Anal. Chem. 1984, 56, 1794-1797.

(6) Eiceman, G. A. G. A.; Yuan-Feng, W.; Garcia-Gonzalez, L.; Harden, C. S. C. S.; Shoff, D. B. D. B. Enhanced Selectivity in Ion Mobility Spectrometry Analysis of Complex Mixtures by Alternate Reagent Gas Chemistry. Anal. Chim. Acta 1995, 306 (1), 21-33.

(7) Monge, M. E.; Fernández, F. M. An Introduction to Ambient Ionization Mass Spectrometry. Ambient Ion. Mass Spectr. 2014, No. 2, $1-22$.

(8) Harris, G. a; Nyadong, L.; Fernandez, F. M. Recent Developments in Ambient Ionization Techniques for Analytical Mass Spectrometry. Analyst 2008, 133 (10), 1297-1301.

(9) Shahin, M. M. Mass-Spectrometric Studies of Corona Discharges. J. Chem. Phys. 1966, 45 (7), 2600-2605.

(10) Shahin, M. M. Use of Corona Discharges for the Study of IonMolecule Reactions. J. Chem. Phys. 1967, 47 (11), 4392-4398.

(11) Fenn, J. B. Ion Formation from Charged Droplets: Roles of Geometry, Energy, and Time. J. Am. Soc. Mass Spectrom. 1993, 4 (7), 524-535.

(12) Yamashita, M.; Fenn, J. B. Negative Ion Production with the Electrospray Ion Source. J. Phys. Chem. 1984, 88 (20), 4671-4675.

(13) Mora, J. F. d. 1.; Van Berkel, G. J.; Enke, C. G.; Cole, R. B.; Martinez-Sanchez, M.; Fenn, J. B. Electrochemical Processes in Electrospray Ionization Mass Spectrometry. J. Mass Spectrom. 2000, 35 (8), 939-952.

(14) Hayen, H.; Michels, A.; Franzke, J. Dielectric Barrier Discharge Ionization for Liquid Chromatography/Mass Spectrometry. Anal. Chem. 2009, 81 (24), 10239-10245.

(15) Guo, C.; Tang, F.; Chen, J.; Wang, X.; Zhang, S.; Zhang, X. Development of Dielectric-Barrier-Discharge Ionization. Anal. Bioanal. Chem. 2015, 407 (9), 2345-2364.

(16) Ahrens, A.; Hitzemann, M.; Zimmermann, S. Miniaturized HighPerformance Drift Tube Ion Mobility Spectrometer. Int. J. Ion Mobility Spectrom. 2019, 22 (2), 77-83.

(17) Kuklya, A.; Reinecke, T.; Uteschil, F.; Kerpen, K.; Zimmermann, S.; Telgheder, U. X-Ray Ionization Differential Ion Mobility Spectrometry. Talanta 2017, 162, 159-166.

(18) Reinecke, T.; Kirk, A. T.; Heptner, A.; Niebuhr, D.; Böttger, S.; Zimmermann, S. A Compact High-Resolution X-Ray Ion Mobility Spectrometer. Rev. Sci. Instrum. 2016, 87, 053120.

(19) Turner, R. B.; Brokenshire, J. L. Hand-Held Ion Mobility Spectrometers. TrAC, Trends Anal. Chem. 1994, 13 (7), 275-280.

(20) Ewing, R. G.; Atkinson, D. A.; Eiceman, G. A.; Ewing, G. J. A Critical Review of Ion Mobility Spectrometry for the Detection of
Explosives and Explosive Related Compounds. Talanta 2001, 54 (3), 515-529.

(21) Koyano, I. Ion-Molecule Reactions. In Comprehensive Chemical Kinetics: Selected Elementary Reactions; Bamford, C. H., Tipper, C. F. H., Eds.; Elsevier, 1976; Vol. 18, pp 293-428.

(22) Munson, M. S. B.; Field, F. H. Physical and Inorganic Chemistry. J. Am. Chem. Soc. 1966, 88 (12), 2621-2630.

(23) Munson, M. S. B.; Field, F. H. Chemical Ionization Mass Spectrometry. I. General Introduction. J. Am. Chem. Soc. 1966, 88 (12), 2621-2630.

(24) Munson, B. Chemical Ionization Mass Spectrometry: Theory and Applications. Encycl. Anal. Chem. 2000, 1-22.

(25) Chen, E. C. M.; Wentworth, W. E.; Desai, E.; Batten, C. F. Importance of Kinetics and Thermodynamics to the Electron-Capture Detector. J. Chromatogr. A 1987, 399 (C), 121-137.

(26) Wentworth, W. E.; Becker, R. S. Potential Method for the Determination of Electron Affinities of Molecules: Application to Some Aromatic Hydrocarbons. J. Am. Chem. Soc. 1962, 84 (22), 4263-4266.

(27) Poole, C. F. Ionization-Based Detectors for Gas Chromatography. J. Chromatogr. A 2015, 1421, 137-153.

(28) Fujii, T. Ion/Molecule Attachment Reactions: Mass Spectrometry 2015, 1.

(29) Ewing, R. G.; Eiceman, G. A.; Stone, J. A. Proton-Bound Cluster Ions in Ion Mobility Spectrometry. Int. J. Mass Spectrom. 1999, 193 (1), $57-68$.

(30) Jurado-Campos, N.; Garrido-Delgado, R.; Martinez-Haya, B.; Eiceman, G. A.; Arce, L. Stabilities of Proton-Bound Clusters of Alkyl Alcohols, Aldehydes and Ketones in Ion Mobility Spectrometry. Talanta 2018, 185, 299-308.

(31) Allers, M.; Kirk, A. T.; Schaefer, C.; Schlottmann, F.; Zimmermann, S. Formation of Positive Product Ions from Substances with Low Proton Affinity in High Kinetic Energy Ion Mobility Spectrometry (HiKE-IMS). Rapid Commun. Mass Spectrom. 2021, 35, $1-13$.

(32) Puton, J.; Nousiainen, M.; Sillanpää, M. Ion Mobility Spectrometers with Doped Gases. Talanta 2008, 76 (5), 978-987.

(33) Hill, C. a; Thomas, C. L. P. A Pulsed Corona Discharge Switchable High Resolution Ion Mobility Spectrometer-Mass Spectrometer. Analyst 2003, 128 (1), 55-60.

(34) McMahon, T. B. High Pressure Mass Spectrometry. In Energetics of Stable Molecules and Reactive Intermediates; Minas da Piedade, M. E., Ed.; Kluwer Academic Press, 1999; pp 259-280.

(35) Lau, Y. K.; Ikuta, S.; Kebarle, P. Thermodynamics and Kinetics of the Gas-Phase Reactions: $\mathrm{H} 3 \mathrm{O}+(\mathrm{H} 2 \mathrm{O}) \mathrm{N}-1+\mathrm{H} 2 \mathrm{O}=\mathrm{H} 3 \mathrm{O}$ $+(\mathrm{H} 2 \mathrm{O})$ N. J. Am. Chem. Soc. 1982, 104 (6), 1462-1469.

(36) Sunner, J.; Nicol, G.; Kebarle, P. Factors Determining Relative Sensitivity of Analytes in Positive. Anal. Chem. 1988, 60, 1300-1307.

(37) Sunner, J.; Nicol, G.; Kebarle, P. Factors Determining Relative Sensitivity of Analytes in Positive Mode Atmospheric Pressure Ionization Mass Spectrometry. Anal. Chem. 1988, 60 (13), 1300-1307.

(38) Nicol, G.; Sunner, J.; Kebarle, P. Kinetics and Thermodynamics of Protonation Reactions: $\mathrm{H} 3 \mathrm{O}+(\mathrm{H} 2 \mathrm{O}) \mathrm{h}+\mathrm{B}=\mathrm{BH}+(\mathrm{H} 2 \mathrm{O}) \mathrm{b}+(\mathrm{h}-\mathrm{b}$ $+1) \mathrm{H} 2 \mathrm{O}$, Where B Is a Nitrogen, Oxygen or Carbon Base. Int. J. Mass Spectrom. Ion Processes 1988, 84 (1-2), 135-155.

(39) Mautner, M. The Ionic Hydrogen Bond and Ion Solvation. 1. NH $+\cdots \mathrm{O}, \mathrm{NH}+\cdots \mathrm{N}$, and $\mathrm{OH}+\cdots \mathrm{O}$ Bonds. Correlations with Proton Affinity. Deviations Due to Structural Effects. J. Am. Chem. Soc. 1984, 106 (5), 1257-1264.

(40) Meot-Ner, M.; Sieck, L. W. The Ionic Hydrogen Bond. 1. Sterically Hindered Bonds. Solvation and Clustering of Protonated Amines and Pyridines. J. Am. Chem. Soc. 1983, 105 (10), 2956-2961.

(41) Mackay, G. I.; Tanner, S. D.; Hopkinson, A. C.; Bohme, D. K. Gas-Phase Proton-Transfer Reactions of the Hydronium Ion at $298 \mathrm{~K}$. Can. J. Chem. 1979, 57 (12), 1518-1523.

(42) Bohme, D. K.; Mackay, G. I.; Tanner, S. D. An Experimental Study of the Gas Phase Kinetics of Reactions with Hydrated H3O+ Ions $(\mathrm{N}=1-3)$ at 298K. J. Am. Chem. Soc. 1979, 101 (14), 3724-3730. 
(43) Bohme, D. K.; Ferreira, M. A. A. Gas Phase Studies of the Influence of Solvation on Ion Reactivity. Ionic Process. Gas Phase 1984, 111.

(44) Zhao, J.; Zhang, R. Proton Transfer Reaction Rate Constants between Hydronium Ion ( $\mathrm{H} 3 \mathrm{O}+)$ and Volatile Organic Compounds. Atmos. Environ. 2004, 38 (14), 2177-2185.

(45) Herron, J. T.; Green, D. S. Chemical Kinetics Database and Predictive Schemes for Nonthermal Humid Air Plasma Chemistry. Part II. Neutral Species Reactions. Plasma Chem. Plasma Process. 2001, 21 (3), 459-481.

(46) Yang, X.; Castleman, A. W. Temperature and Cluster Size Dependence Studies of Reactions of Protonated Water Clusters with Acetonitrile. J. Chem. Phys. 1991, 95 (1), 130-134.

(47) Yang, X.; Zhang, X.; Castleman, A. W. Kinetics and Mechanism Studies of Large Protonated Water Clusters, $\mathrm{H}+(\mathrm{H} 2 \mathrm{O}) \mathrm{n}, \mathrm{n}=1-60$, at Thermal Energy. Int. J. Mass Spectrom. Ion Processes 1991, 109 (C), 339-354.

(48) Kawai, Y.; Yamaguchi, S.; Okada, Y.; Takeuchi, K. Reactions of Protonated Water Clusters $\mathrm{H}+(\mathrm{H} 2 \mathrm{O}) \mathrm{n}(\mathrm{N}=2$ and 4) with $\mathrm{D} 2 \mathrm{O}$, Acetonitrile, Acetone, DMS, DMSO, and Pyridine. J. Mass Spectrom. Soc. Jpn. 2004, 52 (5), 271-276.

(49) Viggiano, A. A.; Dale, F.; Paulson, J. F. Proton Transfer Reactions of $\mathrm{H}+(\mathrm{H} 2 \mathrm{O}) \mathrm{N}=2-11$ with Methanol, Ammonia, Pyridine, Acetonitrile, and Acetone. J. Chem. Phys. 1988, 88 (4), 2469-2477.

(50) Jazan, E.; Tabrizchi, M. Kinetic Study of Proton-Bound Dimer Formation Using Ion Mobility Spectrometry. Chem. Phys. 2009, 355 (1), 37-42.

(51) Andrade, F. J.; Shelley, J. T.; Wetzel, W. C.; Webb, M. R.; Gamez, G.; Ray, S. J.; Hieftje, G. M. Atmospheric Pressure Chemical Ionization Source. 1. Ionization of Compounds in the Gas Phase. Anal. Chem. 2008, 80 (8), 2646-2653.

(52) Matuszak, K. P. The Characterization of Atmospheric Pressure Ionization/Tandem Mass Spectrometry for Direct Atmospherc Analysis. Ph.D dissertation; University of Florida, 1988.

(53) Heptner, A.; Angerstein, N.; Reinecke, T.; Bunert, E.; Kirk, A. T.; Niedzwiecki, I.; Zimmermann, S. Improving the Analytical Performance of Ion Mobility Spectrometer Using a Non-Radioactive Electron Source. Int. J. Ion Mobility Spectrom. 2016, 19 (4), 175-182.

(54) Siegel, M. W. Atmospheric Pressure Ionization. In Plasma Chromatograph; Carr, T. W., Ed.; Plenum Press: New York, 1984; pp 96-113.

(55) Ketkar, S. N.; Penn, S. M.; Fite, W. L. Influence of Coexisting Analytes in Atmospheric Pressure Ionization Mass Spectrometry. Anal. Chem. 1991, 63 (9), 924-925.

(56) Heptner, A.; Cochems, P.; Langejuergen, J.; Gunzer, F.; Zimmermann, S. Investigation of Ion-Ion-Recombination at Atmospheric Pressure with a Pulsed Electron Gun. Analyst 2012, 137 (21), 5105-5112.

(57) Goeringer, D. E. Factors Influencing the Analytical Performance of an Atmospheric Sampling Glow Discharge Ionization Source as Revealed via Ionization Dynamics Modeling. J. Am. Soc. Mass Spectrom. 2003, 14 (11), 1315-1326.

(58) Sunner, J.; Ikonomou, M. G.; Kebarle, P. Sensitivity Enhancements Obtained at High Temperatures in Atmospheric Pressure Ionization Mass Spectrometry. Anal. Chem. 1988, 60 (13), 1308-1313.

(59) Safaei, Z.; Eiceman, G. A. A.; Puton, J.; Stone, J. A. A.; Nasirikheirabadi, M.; Anttalainen, O.; Sillanpää, M. Differential Mobility Spectrometry of Ketones in Air at Extreme Levels of Moisture. Sci. Rep. 2019, 9 (1), 5593.

(60) Safaei, Z.; Willy, T. J.; Eiceman, G. A.; Stone, J. A.; Sillanpää, M. Quantitative Response in Ion Mobility Spectrometry with Atmospheric Pressure Chemical Ionization in Positive Polarity as a Function of Moisture and Temperature. Anal. Chim. Acta 2019, 1092, 144-150.

(61) Ewing, R. G.; Atkinson, D. A.; Clowers, B. H. Direct Real-Time Detection of RDX Vapors under Ambient Conditions. Anal. Chem. 2013, 85 (1), 389-397.

(62) Scott, a. D.; Hunter, E. J.; Ketkar, S. N. Use of a Clustering Reaction To Detect Low Levels of Moisture in Bulk Oxygen Using an
Atmospheric Pressure Ionization Mass Spectrometer. Anal. Chem. 1998, 70 (9), 1802-1804.

(63) Bohme, D. K.; Mackay, G. I.; Tanner, S. D. An Experimental Study of the Gas-Phase Kinetics of Reactions with Hydrated H3O +Ions $(\mathrm{n}=1-3)$ at 298 K. J. Am. Chem. Soc. 1979, 101 (14), 37243730.

(64) Tolmachev, A. V. A.; Clowers, B. H. B.; Belov, M. E.; Smith, R. D. Coulombic Effects in Ion Mobility Spectrometry. Anal. Chem. 2009, 81 (12), 4778-4787.

(65) Jasper, A. W.; Pelzer, K. M.; Miller, J. A.; Kamarchik, E.; Harding, L. B.; Klippenstein, S. J. Predictive a Priori Pressure-Dependent Kinetics. Science (Washington, DC, U. S.) 2014, 346 (6214), 12121215.

(66) Ilbeigi, V.; Tabrizchi, M. Peak-Peak Repulsion in Ion Mobility Spectrometry. Anal. Chem. 2012, 84 (8), 3669-3675.

(67) Sunner, J.; Nicol, G.; Kebarle, P. Factors Determining Relative Sensitivity of Analytes in Positive Mode Atmospheric Pressure Ionization Mass Spectrometry. Anal. Chem. 1988, 60 (13), 1300-1307.

(68) Anttalainen, O.; Lattouf, E.; Kotiaho, T.; Eiceman, G. A. Ion Density of Positive and Negative Ions at Ambient Pressure in Air at 12 to $136 \mathrm{Mm}$ from 4.9 KV Soft X-Ray Source. Rev. Sci. Instrum. 2021, 92, 054104.

(69) Ito, T.; Namiki, N.; Lee, M.; Emi, H.; Otani, Y. Electrostatic Separation of Volatile Organic Compounds by Ionization. Environ. Sci. Technol. 2002, 36 (19), 4170-4174. 